\title{
Increased Levels of Low-Density Lipoprotein Oxidation in Patients with Familial Hypercholesterolemia and in End-Stage Renal Disease Patients on Hemodialysis
}

\author{
Lambertus van Tits, Jacqueline de Graaf, Heidi Hak-Lemmers, Sebastian Bredie, \\ Pierre Demacker, Paul Holvoet, and Anton Stalenhoef
}

Department of Medicine ( $L v T, J d G, H H-L, S B, P D, A S)$, Division of General Internal Medicine, UMC Nijmegen, Nijmegen, The Netherlands; and Center for Experimental Surgery and Anesthesiology (PH), Catholic University of Leuven, Leuven, Belgium

SUMMARY: Patients with familial hypercholesterolemia $(\mathrm{FH})$ and patients with end-stage renal disease (ESRD) undergoing dialysis suffer from accelerated atherosclerosis. Oxidation of low-density lipoprotein (LDL) cholesterol is crucial in atherogenesis. In the present study, we determined the LDL oxidation level and oxidizability of isolated LDL of 11 male patients with $\mathrm{FH}, 15$ male ESRD patients on hemodialysis, and 15 age-matched male normolipidemic healthy controls. FH patients were without lipid-lowering medication for at least 4 weeks and were reassessed after 2 years of cholesterol-lowering therapy (statins). LDL oxidation level was measured by ELISA using monoclonal antibody 4E6 to oxidized LDL (oxLDL) as the capture antibody and anti-human apoB antibody for detection; results were expressed as percentage oxLDL. In FH patients and in ESRD patients on hemodialysis, both groups having a higher percentage of cardiovascular disease, mean plasma LDL oxidation levels were significantly elevated compared with controls ( $4.9 \pm 1.3 ; 3.7 \pm 2.0 ; 1.7 \pm 0.6 \%$, respectively). Within each group of subjects, LDL oxidation level was not associated with history of cardiovascular disease. Furthermore, in neither group was a significant correlation found between plasma concentration of LDL cholesterol and LDL oxidation level. After cholesterol-lowering therapy, LDL oxidation level in $\mathrm{FH}$ patients had not changed significantly and remained elevated compared with controls, despite a reduction of LDL cholesterol by $55 \%$ on average. Also, absolute plasma oxLDL concentrations, obtained by multiplying LDL oxidation level with plasma LDL cholesterol concentration, were significantly higher in FH patients before and after cholesterollowering therapy and in ESRD patients on hemodialysis than in controls $(489 \pm 145 ; 189 \pm 122 ; 100 \pm 65$; and $59 \pm 27 \mu \mathrm{moles} / \mathrm{L}$, respectively). No correlation was found between plasma oxLDL concentration and parameters of LDL oxidizability, LDL fatty acids, and LDL alpha-tocopherol content. We conclude that cholesterol-lowering therapy does not normalize elevated LDL oxidation levels in $\mathrm{FH}$ patients and elevated LDL oxidation level in FH and in ESRD might mirror atherosclerosis. (Lab Invest 2003, 83:13-21).

\begin{abstract}
$D$ atients with familial hypercholesterolemia $(\mathrm{FH})$ 1 and patients with end-stage renal disease (ESRD) undergoing dialysis have a higher mortality rate because of complications of atherosclerosis than the general population (Lindner et al, 1974; Locatelli et al, 1998; Simon Broome Register Group, 1991; Slack, 1969). For both patient groups, this finding cannot be attributed solely to the traditional risk factors of atherosclerosis such as hypertension and dyslipidemia because there is substantial variation in the onset, rate, and severity of atherosclerotic disease among patients who are matched for these classical risk factors (Foley and Parfrey, 1998; Foley et al, 1998; Kotze et al, 1993; Thompson et al, 1989). Nowadays,
\end{abstract}

\section{DOI: 10.1097/01.LAB.0000048633.76607.E0}

Received July 9, 2002.

Supported by a grant from the Netherlands Heart Foundation (2001.038). Address reprint requests to: Dr. L.J. H. van Tits, Department of Medicine, Division of General Internal Medicine 564, University Medical Center Nijmegen, Geert Grooteplein Zuid 8, P.O. Box 9101, 6500 HB Nijmegen, The Netherlands.E-mail:B.vanTits@aig.umcn.nl atherosclerosis is regarded as a chronic inflammatory disease in which low-density lipoprotein (LDL) cholesterol plays a crucial role (Ross, 1986, 1993). However, native LDL needs to be oxidatively modified before it exerts its proinflammatory and atherogenic properties in full (Steinberg and Lewis, 1997; Witztum and Steinberg, 1991). Only after its oxidative modification is LDL excessively taken up by macrophages via the scavenger receptor pathway (Haberland et al, 1982), leading to the formation of foam cells characteristic of the earliest atherosclerotic lesion. In this way conditions of oxidative stress can accelerate the atherosclerotic process.

In patients with $\mathrm{FH}$, because of reduced receptormediated hepatic LDL uptake, plasma concentration of LDL cholesterol is severely elevated and circulation residence time of LDL particles is prolonged (Goldstein et al, 1995; Myant, 1983). These conditions favor modification of LDL to particles that are more electronegative (Demuth et al, 1996) and exhibit enhanced oxidizability (Sevanian et al, 1996). Indeed, in FH, increased electronegative LDL proportion and increased indices of oxidative stress in plasma were 
recently reported (Nourooz-Zadeh et al, 2001; Sanchez-Quesada et al, 1999). However, in disagreement with these findings, LDL oxidizability was not different from controls (Sanchez-Quesada et al, 1999) and antibody titers to oxidized LDL (oxLDL) were not elevated in $\mathrm{FH}$ (Hulthe et al, 1998). Until now more specific and direct information on the oxidative status of LDL in $\mathrm{FH}$ had been lacking. Patients with ESRD, whose altered lipoprotein profile is characterized by reduced high-density lipoprotein (HDL) cholesterol, moderate hypertriglyceridemia, and increased levels of remnants and lipoprotein(a) (Attman et al, 1993), are generally accepted to be subject to increased oxidative stress. During hemodialysis, the bioincompatibility of the dialysis membrane leads to activation of humoral and cellular components of the immune system, including free radical-producing granulocytes and platelets (Bos et al, 1997; Cases et al, 1993). Hemodialysis reportedly is associated with depletion of antioxidants and increased levels of lipid peroxidation products in plasma (Handelman et al, 2001; Jackson et al, 1995; Loughrey et al, 1994a). However, with respect to oxidative modification of LDL as assessed by indirect measurements, findings are not consistent. Although some groups report elevated levels of autoantibodies to oxLDL (Maggi et al, 1994a, 1994b), increased LDL oxidizability (Maggi et al, 1994a; Panzetta et al, 1995), and reduced alpha-tocopherol content of LDL (Panzetta et al, 1995) in dialysis patients compared with healthy controls, others could not confirm these differences but did demonstrate that LDL of chronic renal failure patients was more atherogenic (Islam et al, 2000; O'Byrne et al, 2001). It has been suggested that these inconsistencies are partly a result of the variable methodologies used and of abnormal LDL composition in dialysis patients (Devaraj and Jialal, 1997; Loughrey et al, 1994b). Moreover, LDL oxidizability is a nonphysiologic assay in which a high concentration of metal ion is used, and most factors relevant for oxidation of LDL in vivo, such as antioxidants and $\mathrm{HDL}$, are lacking. The recent development of monoclonal antibodies to epitopes of oxLDL has made it possible to directly determine the amount of oxidatively modified LDL particles present in the circulation (Holvoet et al, 1996; Itabe et al, 1996). In the present study, we used a monoclonal antibodybased immunoassay to study plasma LDL oxidation levels in $\mathrm{FH}$ patients before and after cholesterollowering therapy, in ESRD patients on hemodialysis, and in normolipidemic healthy controls. In addition we determined the susceptibility of LDL to in vitro oxidation and we measured fatty acids and alphatocopherol in LDL.

\section{Results and Discussion}

Data summarized in Table 1 show that mean age and smoking behavior were not significantly different between groups. Cardiovascular disease (CVD) was more frequent in ESRD patients on hemodialysis and in $\mathrm{FH}$ than in controls, but the number of CVD events may not fully reflect the severity of the atherosclerotic disease in the patients. Using B-mode ultrasound, a technique that visualizes atherosclerotic changes in the walls of arteries, it has been demonstrated that carotid artery intima-media thickness is markedly increased, plaque is more frequent, and calcified plaque is common in $\mathrm{FH}$ and in ESRD (Haraki et al, 2001; Lavrencic et al, 1996; Pannier et al, 2000; Savage et al, 1998; Smilde et al, 1998; Tonstad et al, 1998). Thus, atherosclerotic disease is underestimated in $\mathrm{FH}$ and in ESRD if presented as CVD events only.

In ESRD patients plasma concentrations of total cholesterol and LDL cholesterol were significantly lower and triglycerides significantly higher than in controls. Plasma concentration of HDL cholesterol did not differ between ESRD patients and controls. FH patients had significantly higher plasma concentrations of total cholesterol, triglycerides, and LDL cholesterol at baseline compared with controls, but plasma concentrations of HDL cholesterol were not different.

After baseline determinations, $\mathrm{FH}$ patients received cholesterol-lowering medication for 2 years: five patients received atorvastatin ( $80 \mathrm{mg}$ daily) and six patients received simvastatin (40 mg daily). After therapy, concentrations of total cholesterol, triglycerides, and LDL cholesterol had decreased significantly, but

Table 1. Characteristics of Normolipidemic Healthy Controls, Patients with ESRD on Hemodialysis, and Patients with FH Before and After Cholesterol-Lowering Therapy

\begin{tabular}{|c|c|c|c|c|}
\hline & \multirow[b]{2}{*}{ Controls } & \multirow[b]{2}{*}{ ESRD } & \multicolumn{2}{|c|}{$\mathrm{FH}$} \\
\hline & & & Baseline & After therapy \\
\hline Number of subjects & 15 & 15 & 11 & 11 \\
\hline Age $(y r)$ & $54 \pm 11$ & $56 \pm 15$ & $53 \pm 8$ & $55 \pm 8$ \\
\hline Smoker & $6 / 15(40 \%)$ & $5 / 15(33 \%)$ & \multicolumn{2}{|c|}{$3 / 11(27 \%)$} \\
\hline CVD & $1 / 15(7 \%)$ & $7 / 15(47 \%)$ & \multicolumn{2}{|c|}{$6 / 11(55 \%)$} \\
\hline Total cholesterol (mм) & $4.94 \pm 0.62$ & $4.39 \pm 0.86^{a}$ & $12.0 \pm 1.4^{c}$ & $5.9 \pm 1.0^{a, e}$ \\
\hline Triglycerides (mм) & $0.98 \pm 0.39$ & $1.75 \pm 1.07^{a}$ & $2.16 \pm 0.73^{c}$ & $1.34 \pm 1.16^{d}$ \\
\hline HDL cholesterol (mм) & $1.17 \pm 0.30$ & $0.94 \pm 0.32$ & $1.01 \pm 0.31$ & $1.05 \pm 0.24$ \\
\hline LDL cholesterol (mM) & $3.46 \pm 0.61$ & $2.61 \pm 0.69^{b}$ & $10.06 \pm 1.39^{c}$ & $4.30 \pm 0.86^{a, e}$ \\
\hline
\end{tabular}

${ }^{a} p<0.05,{ }^{b} p<0.01,{ }^{c} p<0.001$ ( $t$ test versus controls), ${ }^{d} p<0.01,{ }^{e} p<0.000001$ (paired $t$ test versus baseline). HDL, high-density lipoprotein; LDL, low-density lipoprotein; ESRD, end-stage renal disease; FH, familial hypercholesterolemia; CVD, cardiovascular disease. 
total cholesterol and LDL cholesterol were still significantly higher than in controls. No change was observed for plasma HDL cholesterol concentration after therapy.

Table 2 shows the oxidation levels of LDL of subjects as measured by sandwich ELISA in isolated LDL preparations and given in percentage LDL that is oxidatively modified equal to or more extensively than the standard preparation used. In normolipidemic healthy controls, LDL oxidation level ranged from $1 \%$ to $3 \%$. In ESRD patients on hemodialysis and in $\mathrm{FH}$ patients, a 2 -fold higher range in LDL oxidation level was observed (1-7\% and 3-7\%, respectively), resulting in significantly elevated mean values compared with controls. The finding that both patient groups have higher percentages of CVD and increased LDL oxidation levels compared with controls is consistent with the hypothesis that circulating oxLDL is a sensitive marker of coronary artery disease (Ehara et al, 2001; Holvoet et al, 1998b, 2001; Toshima et al, 2000). We did not, however, find an association between history of CVD and LDL oxidation level within each of the two patient groups. Recently, when we studied the effect of statin therapy on LDL oxidation level in 28 patients with chronic renal failure, we also observed no differences between LDL oxidation levels (determined both directly in plasma as well as in isolated LDL) of patients with and without clinical manifestation of CVD (Van den Akker et al, 2003). The lack of a correlation of circulating oxLDL with CVD in FH and in chronic renal failure patients may be due to the fact that the number of CVD events does not fully reflect the severity of the atherosclerotic disease in these patients because subclinical stages are not accounted for. Recently Holvoet et al (2001) found that obese subjects without clinical evidence of CVD but with increased intima/media thickness of carotid arteries had increased circulating oxLDL that was correlated with intima/media thickness, suggesting that an increased oxLDL level is a marker of early atherosclerosis. Thus, increased levels of LDL oxidation in $\mathrm{FH}$ and in ESRD may mirror the atherosclerotic disease, and prospective studies in large groups of patients to evaluate plasma oxLDL and subclinical atherosclerosis in relation to CVD are warranted.

We also assessed the dependency of LDL oxidation level on plasma LDL cholesterol concentration. A significant correlation was not found between plasma concentration of LDL cholesterol and LDL oxidation level in normolipidemic healthy controls or in ESRD patients on hemodialysis or in $\mathrm{FH}$ patients (Fig. 1).

Recently vascular endothelial cells were shown to express a specific lectin-like receptor for oxLDL (LOX1), linking circulating oxLDL with atherogenesis (Moriwaki et al, 1998; Sawamura et al, 1997). Binding of oxLDL to LOX-1 induces superoxide generation and concomitant decrease of nitric oxide, activation of nuclear factor- $\kappa \mathrm{B}$, up-regulation of LOX-1 expression, expression of chemokines and adhesion molecules, and apoptosis, thus affecting atherogenesis from early lesion development to plaque rupture (Cominacini et al, 2000, 2001; Li and Mehta, 2000a, 2000b; Kume et al, 1998). Mice overexpressing this receptor suffer from accelerated atherosclerosis (Sawamura and Inoue, 2001). In ESRD and in $\mathrm{FH}$, enhanced activation of the atherogenic LOX-1 by increased plasma levels of oxLDL may lead to accelerated atherosclerosis.

The results of the sandwich ELISA were used to calculate individual absolute plasma oxLDL concentrations by multiplying LDL oxidation level with plasma LDL cholesterol concentration. As shown in Figure 2, plasma oxLDL concentrations in ESRD patients on hemodialysis were significantly higher than in controls (100 \pm 65 and $59 \pm 27 \mu \mathrm{mol} / \mathrm{L}$, respectively, $p<$ 0.05). Thus, despite the low plasma concentrations of LDL cholesterol in ESRD, a high LDL oxidation level

Table 2. LDL Oxidation Levels, Oxidizability, Fatty Acid Content, and Alpha-Tocopherol Concentration of Normolipidemic Healthy Controls, Patients with ESRD on Hemodialysis, and Patients with FH Before and After Cholesterol-Lowering Therapy

\begin{tabular}{|c|c|c|c|c|}
\hline & \multirow[b]{2}{*}{ Controls } & \multirow[b]{2}{*}{ ESRD } & \multicolumn{2}{|c|}{$\mathrm{FH}$} \\
\hline & & & Baseline & After therapy \\
\hline Number of subjects & 15 & 15 & 11 & 11 \\
\hline \multicolumn{5}{|l|}{ OxLDL (\%) } \\
\hline Mean \pm SD & $1.7 \pm 0.6$ & $3.7 \pm 2.0^{b}$ & $4.9 \pm 1.3^{c}$ & $4.4 \pm 2.6^{b}$ \\
\hline Range & $0.8-2.7$ & $0.7-6.8$ & $2.7-7.3$ & $0.9-8.5$ \\
\hline \multicolumn{5}{|l|}{ LDL oxidizability } \\
\hline Lagtime (min) & $77.8 \pm 7.6$ & $86.7 \pm 9.9^{a}$ & $70.6 \pm 6.5^{a}$ & $68.1 \pm 7.1^{b}$ \\
\hline Rate (nmol/min/mg LDL protein) & $10.5 \pm 2.0$ & $9.2 \pm 1.2$ & $16.0 \pm 1.7^{c}$ & $14.1 \pm 2.5^{b, b *}$ \\
\hline Dienes (nmol/mg LDL protein) & $540 \pm 75$ & $513 \pm 72$ & $665 \pm 65^{c}$ & $559 \pm 82^{c *}$ \\
\hline \multicolumn{5}{|l|}{ LDL FA content ( $\mu \mathrm{mol} / \mathrm{gm}$ LDL protein) } \\
\hline $16: 0+18: 0$ & $1100 \pm 189$ & $1390 \pm 298^{b}$ & $1391 \pm 365^{a}$ & $1136 \pm 283^{a \star}$ \\
\hline $18: 1$ & $778 \pm 151$ & $1065 \pm 230^{b}$ & $836 \pm 188$ & $738 \pm 139$ \\
\hline $18: 2+20: 4$ & $2251 \pm 384$ & $2076 \pm 336$ & $2693 \pm 490^{a}$ & $2145 \pm 584^{b *}$ \\
\hline LDL alpha-tocopherol ( $\mu \mathrm{mol} / \mathrm{mmol} \mathrm{LDL})$ & $2.9 \pm 0.7$ & $2.6 \pm 0.5$ & $3.2 \pm 0.5$ & $2.8 \pm 0.8$ \\
\hline
\end{tabular}

${ }^{a} p<0.05,{ }^{b} p<0.01,{ }^{c} p<0.001$ ( $t$ test versus controls); * paired $t$ test versus baseline. oxLDL, oxidized LDL; FA, fatty acids; 16:0, palmitic acid; 18:0, stearic acid; 18:1, oleic acid; 18:2, linoleic acid; 20:4, arachidonic acid. 


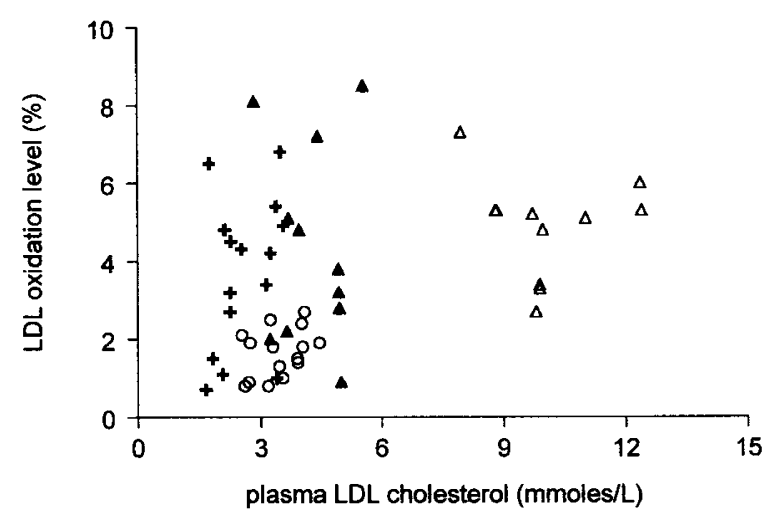

Figure 1.

Relation between plasma low-density lipoprotein (LDL) cholesterol concentration and LDL oxidation level of normolipidemic healthy controls (open circles), end-stage renal disease (ESRD) patients on hemodialysis (crosses), and familial hypercholesterolemia (FH) patients before (open triangles) and after (filled triangles) cholesterol-lowering medication.

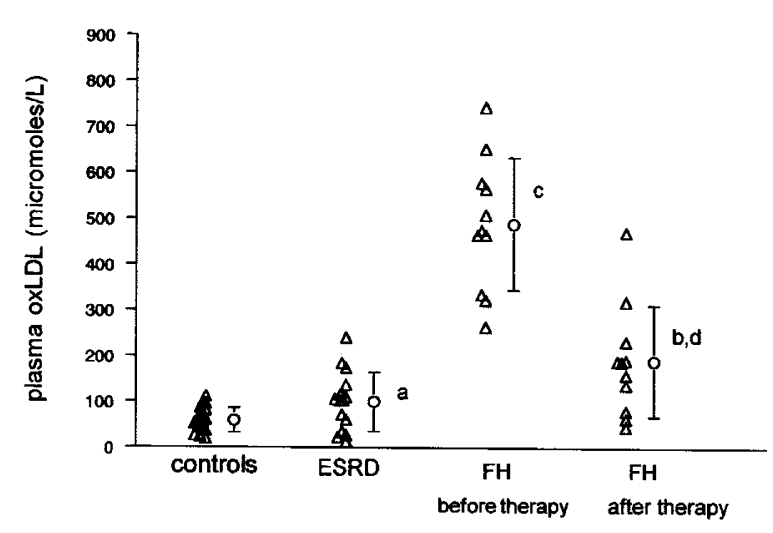

Figure 2.

Scatter graph illustrating individual plasma oxidized LDL (oxLDL) levels and the mean \pm SD values of $0 x L D L$ levels in normolipidemic healthy control subjects, ESRD patients on hemodialysis, and $\mathrm{FH}$ patients before and after cholesterol-lowering therapy. $\left({ }^{\mathrm{a}} p<0.05,{ }^{\mathrm{b}} p<0.01,{ }^{\mathrm{c}} p<0.00001, t\right.$ test versus controls; ${ }^{d} p<0.0001$, paired $t$ test versus baseline).

results in increased plasma concentrations of oxLDL in these patients. In $\mathrm{FH}$ the combined presence of elevated LDL oxidation level and severely increased plasma LDL cholesterol concentration results in an approximately 8-fold increased level of oxLDL in plasma (489 $\pm 145 \mu \mathrm{mol} / \mathrm{L})$ compared with normolipidemic controls. After cholesterol-lowering therapy, plasma levels of oxLDL in $\mathrm{FH}$ decreased significantly $(-65 \pm 18 \%)$ to $189 \pm 122 \mu \mathrm{mol} / \mathrm{L}$ because of the strong decrease in plasma LDL cholesterol concentration $(-55 \pm 5 \%)$ but remained significantly higher than in controls (Fig. 2). As expected, calculated plasma oxLDL concentrations correlated with plasma LDL cholesterol (Fig. 3). The highest correlation was found when all samples were analyzed $(r=0.88, p<0.0001$, $n=52$ ), but correlation was significant also within the subgroups of controls ( $r=0.68, p=0.005, n=15)$, ESRD patients on hemodialysis $(r=0.67, p=0.006$, $n=15)$, and $\mathrm{FH}$ patients $(r=0.81, p<0.0001, n=$ 22). In Figure 3, all FH patients but one, and all ESRD patients on hemodialysis but one, are located above

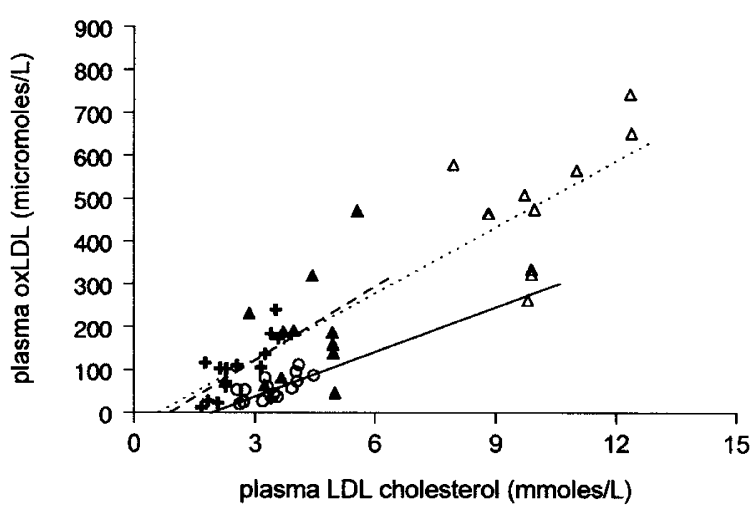

Figure 3

Correlation between plasma LDL cholesterol concentrations and plasma oxLDL levels. The solid, broken, and dotted lines represent regression lines for normolipidemic healthy controls (open circles), hemodialysis patients with ESRD (crosses), and FH patients before (open triangles) and after (closed triangles) lipid-lowering therapy, respectively.

the regression line of the control group, indicating that the LDL oxidation levels of these patients are increased compared with those of controls.

In the present study, in FH patients but not in ESRD patients, increased plasma oxLDL concentration was accompanied by increased susceptibility of LDL to in vitro oxidation, as reflected by decreased lagtime, despite normal LDL alpha-tocopherol content (Table 2). These data on LDL oxidizability were supported by measurements of fatty acids: LDL from FH patients contained increased amounts of polyunsaturated fatty acids, which are a substrate of lipid peroxidation, whereas LDL from ESRD patients was relatively rich in nonoxidizable saturated and monounsaturated fatty acids (Table 2). Consistently, the rate of diene production and the amount of dienes produced were higher in $\mathrm{FH}$ patients but not in ESRD patients compared with controls (Table 2). The present data are in agreement with our previously published results, in which we showed that fatty acid composition modulates LDL oxidizability (Kleinveld et al, 1993). ESRD patients, however, were supplemented daily with a vitamin mix, and this could have contributed to the increased resistance of LDL to oxidation. The finding that despite vitamin supplementation alpha-tocopherol concentration in LDL of ESRD patients was not elevated, suggests increased consumption of alpha-tocopherol because of oxidative stress.

Previously, similar LDL susceptibility to in vitroinduced oxidation in combination with increased electronegative LDL proportion were observed in untreated FH patients compared with controls (SanchezQuesada et al, 1999). However, the use of variable methodologies to assay LDL oxidizability make it difficult to compare data obtained in different studies.

After cholesterol lowering in FH, LDL fatty acids had normalized and the rate of diene production and the amount of dienes produced had significantly decreased, but lagtime of oxidation had not increased (Table 2). No significant correlation was found between plasma oxLDL concentration and parameters of LDL oxidizability (lagtime, rate of diene production, 
dienes produced), LDL fatty acids, and LDL alphatocopherol content.

The LDL oxidation levels that we observed in controls and in ESRD patients on hemodialysis are somewhat higher than those reported by Holvoet et al (1996), who measured oxLDL in plasma samples of such subjects directly using the same monoclonal antibody to oxLDL in a competitive immunoassay. In their system, calculated LDL oxidation levels amounted to $0.5 \%$ in controls and $2.7 \%$ in severe chronic renal failure patients who were on hemodialysis therapy (Holvoet et al, 1996). Reportedly, a standard oxLDL preparation, containing on the average 210 substituted lysines per apolipoprotein B-100 (apoB-100) molecule, was used to quantitate oxLDL. In the present study, we used a standard oxLDL preparation, containing on the average 48 substituted lysines per apoB-100 molecule. This amount of lysine substitution is nearly sufficient to enable the interaction of LDL with the scavenger receptor (Haberland et al, 1982). More extensive oxidation of the standard LDL preparation would have resulted in a further shift to the left of the calibration curve in our system and in a reduction of LDL oxidation levels of samples to values comparable with those reported by Holvoet et al (1996). Itabe et al (1996) recently also reported data on LDL oxidation levels in patients who were on hemodialysis treatment. Their system was identical to ours, except that they used a monoclonal antibody that was directed to oxidized products of phosphatidylcholine. Although the LDL oxidation levels that they reported were about 50-fold lower than ours and others found using 4E6 (which is very likely explained by the differential antigenic properties of these monoclonal antibodies), they also observed increased oxidative modification of LDL in hemodialysis patients.

To our knowledge this is the first report on LDL oxidation levels in $\mathrm{FH}$. We demonstrated that without cholesterol-lowering medication, LDL oxidation levels are elevated in patients with $\mathrm{FH}$ compared with normolipidemic healthy controls. We also show that after cholesterol-lowering therapy, LDL oxidation level in $\mathrm{FH}$ patients had not changed significantly and remained elevated compared with controls (Table 2). This is in agreement with a recent report showing no difference between oxLDL levels of patients with CVD receiving 3-hydroxy-3methylglutaryl coenzyme $A$ reductase inhibitors compared with levels of patients with CVD who did not receive therapy (Toshima et al, 2000). It also supports our observation that LDL oxidation level is not associated with plasma LDL cholesterol concentration in $\mathrm{FH}$ (Fig. 1).

At present it is not clear whether the plasma LDL oxidation level reflects oxidative processes that take place in the circulation or mirrors the extent and/or severity of atherosclerosis in the vascular wall. Our finding that plasma oxLDL does not correlate with in vitro LDL oxidation suggests that oxidative processes in the circulation are not the source of plasma oxLDL. However, in vitro LDL oxidation may not be a suitable model to monitor in vivo oxidative processes. These may be monitored more accurately by measuring plasma and urine levels of F2 isoprostanes, a unique series of prostaglandin-like compounds formed in vivo by nonenzymatic free radical-catalyzed peroxidation of arachidonic acid (Morrow, 2000). Increased levels of F2 isoprostanes have been shown previously in $\mathrm{FH}$ and in ESRD (Davi et al, 1997; Handelman et al, 2001; Nourooz-Zadeh et al, 2001). It therefore seems tempting to relate the increased LDL oxidation levels found in $\mathrm{FH}$ and in ESRD patients on hemodialysis in the present study to increased oxidative stress. However, recently it was reported that supplementation with alpha-tocopherol dose dependently decreased urinary F2 isoprostanes in hypercholesterolemic subjects (Davi et al, 1997) and reduced LDL oxidizability (Islam et al, 2000) but did not affect the elevated atherogenicity of LDL (which is a measure of oxidative modification) of renal failure patients on dialysis (O'Byrne et al, 2001). Thus these data also suggest that plasma oxLDL does not result from oxidative processes in the circulation. This finding and the present observation that ESRD patients on hemodialysis receiving vitamin supplements have reduced LDL oxidizability in combination with increased LDL oxidation level, indicate that the atherogenic modification of the oxLDL particle has occurred outside the reach of alpha-tocopherol and that alpha-tocopherol may reduce the oxidizability of circulating particles but cannot restore the modification that the particles may have previously obtained elsewhere. In FH, theoretically, a prolonged residence of LDL in the circulation might enable these oxidative modifications, even in the absence of increased oxidative stress. However, the present finding that statin treatment did not influence LDL oxidation levels despite substantial lowering of plasma LDL cholesterol concentration, suggests that plasma oxLDL in $\mathrm{FH}$ is not generated in the circulation in relation to the residence time of LDL. Rather, the characteristics of circulating oxLDL and the relationship of oxLDL levels with the severity of coronary syndromes (Holvoet et al, 1995) suggest that oxLDL is generated and released into the blood stream at sites of plaque erosion or rupture by cellmediated processes. Thus, we speculate that circulating oxLDL particles in ESRD and in $\mathrm{FH}$ do not result from oxidative processes in the circulation but are a marker of the severity of atherosclerosis. Furthermore, the lack of an association of LDL oxidation levels with plasma LDL cholesterol concentration, LDL oxidizability, and LDL alpha-tocopherol content in ESRD patients on hemodialysis and in $\mathrm{FH}$ patients suggests that raised LDL oxidation level might be an independent risk factor for CVD.

In conclusion, we show that both in ESRD patients on hemodialysis and in $\mathrm{FH}$ patients, before as well as after cholesterol-lowering therapy, oxidation level of circulating LDL is increased. An enhanced oxidation of LDL might reflect ongoing atherosclerosis in these patients. Future studies should be aimed at unraveling the role of circulating oxLDL particles in complications of atherosclerotic disease in FH and in ESRD. 


\section{Materials and Methods}

\section{Subjects}

The present study included 15 male normotensive hemodialysis patients with ESRD who did not have diabetes mellitus or primary hyperlipidemia and who were not using lipid-lowering drugs, 11 male patients with $\mathrm{FH}$, and 15 male normolipidemic healthy controls. Information about smoking habits and history of CVD was obtained from all subjects. $\mathrm{FH}$ patients were without lipid-lowering medication for at least 4 weeks at the start of the study and were reassessed after cholesterol-lowering therapy for 2 years (simvastatin $40 \mathrm{mg}$ daily or atorvastatin $80 \mathrm{mg}$ daily). Written informed consent was obtained from all participants. The study was approved by the ethics committee of our institution.

Blood samples from patients and controls were obtained under fasting conditions and placed in $\mathrm{K}_{2}$ ethylenediaminetetra-acetate $(1.8 \mathrm{mg} / \mathrm{ml})$ containing vials and in vials without anticoagulant at $4^{\circ} \mathrm{C}$. Serum samples were prepared from blood allowed to clot by centrifugation, and lipids were determined freshly. Plasma samples were prepared by centrifugation within 30 minutes of collection, supplemented with saccharose $(0.6 \%, \mathrm{w} / \mathrm{v})$ to prevent formation of LDL aggregates, and stored at $-80^{\circ} \mathrm{C}$ until analysis of oxLDL. As confirmed in a subgroup of samples, duration of storage did not influence the amount of oxLDL measured (data not shown).

\section{Measurement of oxLDL}

oxLDL was measured by a sandwich ELISA method using the monoclonal antibody 4E6 (generously supplied by Dr. Holvoet from the Center for Experimental Surgery and Anesthesiology, Catholic University of Leuven, Leuven, Belgium) as the capture antibody and anti-human apoB-100 polyclonal antibody for detection. Monoclonal antibody 4E6 is directed against a conformational epitope in the apoB-100 moiety of LDL that is generated as a consequence of aldehyde substitution of lysine residues of apoB-100 (Holvoet et al, 1996). Thus the antibody is specific for oxidatively modified LDL (Holvoet et al, 1998a). We raised the polyclonal anti-human apoB-100 antibody in a goat; it is used for routine immunonephelometric measurement of apoB-100.

Unlike Holvoet, to avoid matrix effects, we separated the LDL fraction from blood plasma by singlespin density gradient ultracentrifugation before the ELISA procedure (Demacker et al, 1983). Moreover, by assaying isolated LDL, the ELISA directly yields the percentage of LDL (see below) that is oxidatively modified equal to or more extensively than the standard preparation used. Previously we have checked the validity of our assay by comparing it with direct measurement of oxLDL in plasma. We observed good correlation $(r=0.72, p<0.0001, n=52)$ between the measurement of oxLDL in isolated LDL and in plasma, showing that the assay specifically detects oxLDL in LDL.
Protein was measured by the method of Lowry et al (1951), using BSA as standard and with chloroform extraction of the color solution to remove turbidity. Each LDL fraction was assayed in the ELISA in two to three different concentrations. Diluted LDL fractions (3.1-12.5 $\mu \mathrm{g} / \mathrm{ml}$ in PBS containing $0.25 \mathrm{~mm}$ EDTA and $0.1 \%$ BSA) were added to the microtiter wells that were precoated with $0.5 \mu \mathrm{g}$ of the antibody 4E6. After extensive washing with PBS containing $0.05 \%(\mathrm{w} / \mathrm{v})$ Tween-20 (Sigma-Aldrich), the remaining oxLDL was detected with the goat anti-apoB-100 antibody and a peroxidase-conjugated rabbit anti-goat $\lg G$ antibody (Sigma-Aldrich). In each ELISA plate, various concentrations of standard oxLDL $(10-2000 \mathrm{ng} / \mathrm{ml}$ in PBS containing $0.25 \mathrm{~mm}$ EDTA and $0.1 \% \mathrm{BSA}$ ) were run simultaneously to determine a standard curve. oxLDL in samples was expressed as percentage of oxLDL ( = LDL oxidation level) by relating the amount of oxLDL detected to the amount of LDL added to the well. Standard oxLDL was prepared from pooled LDL, which was frozen in the presence of $10 \%(\mathrm{w} / \mathrm{v}) \mathrm{sac}-$ charose and $0.1 \mathrm{~mm}$ EDTA and dialyzed against $10 \mathrm{~mm}$ phosphate buffer ( $\mathrm{pH} 7.4$ ) containing $0.9 \% \mathrm{NaCl}$ before oxidation with copper (20 $\mu \mathrm{M}$ copper, 650-700 $\mathrm{mg} / \mathrm{L} \mathrm{LDL}, 15$ hours, $37^{\circ} \mathrm{C}$ ). Using this method, conjugated dienes in LDL reproducibly increased $4.5-$ to 5.0-fold, fluorescence increased 25-fold, and electrophoretic mobility in agarose gel increased markedly and consistently: relative to native LDL, the center of the oxLDL band migrated 4.0 times further. ApoB-100 molecules of oxLDL standard contained on average 48 substituted lysines, as calculated from the number of malondialdehyde molecules bound per molecule of apoB-100, assuming that two lysines on apoB-100 are blocked by each bound malondialdehyde molecule.

To test whether the goat anti-apoB-100 antibody is able to recognize apoB-100 of oxLDL, we performed immunonephelometric measurements of human apoB-100 with the antibody. The results showed that recognition of apoB-100 by the antibody was not disturbed by oxidation of the LDL with copper. After incubation with copper, conjugated dienes in LDL increased gradually from $199 \mathrm{nmol} / \mathrm{mg}$ protein to 224 , $275,780,756$, and $932 \mathrm{nmol} / \mathrm{mg}$ protein at $1.25,2.5$, $5,7.5$ and 15 hours, respectively, whereas apoB-100 concentration as determined by immunonephelometry did not decrease but increased slightly from $566 \mathrm{mg} / \mathrm{L}$ to $630,648,685,728$ and $729 \mathrm{mg} / \mathrm{L}$, respectively. Thus, the antibody is suitable to detect apoB-100 of oxLDL captured by the monoclonal antibody 4E6.

In the ELISA, $\mathrm{EC}_{50}$ of native LDL amounted to about $10 \mu \mathrm{g} / \mathrm{ml}$. Oxidation of LDL caused a parallel shift to the left of the concentration-effect curve, resulting in $\mathrm{EC}_{50}$ values of about $5 \mu \mathrm{g} / \mathrm{ml}, 1 \mu \mathrm{g} / \mathrm{ml}$, and $100 \mathrm{ng} / \mathrm{ml}$ for LDL oxidized with copper for 20 minutes, 40 minutes, and 15 hours, respectively.

Serial dilution of native LDL samples gave results close to linearity (data not shown), indicating that the assay was quantitative and confirming parallelism between the oxLDL standard and native LDL samples. Furthermore, coincubation of LDL samples $(5 \mu \mathrm{g})$ with the monoclonal antibody 4E6 $(0.5 \mu \mathrm{g})$ (almost) com- 
pletely inhibited the binding of apoB-100 to the precoated wells, showing that the oxLDL in this sandwich ELISA was specifically bound to the monoclonal antibody.

\section{Other Methods}

Cholesterol and triglyceride concentrations in serum were determined by enzymatic methods (BoehringerMannheim, Mannheim, Germany) on a Hitachi 747 analyzer (Hitachi, Tokyo, Japan). Serum HDL cholesterol was determined after precipitation of LDL, very low-density lipoprotein, and chylomicrons using phosphotungstate/ $\mathrm{Mg}^{2+}$ (Demacker et al, 1997). LDL cholesterol in serum was calculated using the Friedewald formula (Friedewald et al, 1972). Malondialdehyde in oxLDL samples was determined as thiobarbituric acid reactive substances according to the method described by Conti et al (1991) with minor modifications (van Tits et al, 2001). Concentrations of alphatocopherol were analyzed by reversed-phase HPLC (De Graaf et al, 1991). Fatty acid measurements in LDL were performed by gas chromatography on a $30 \mathrm{~m} \times$ $0.25 \mathrm{~mm}$ inner diameter DB-23 column (J\&W Scientific) as described earlier (Kleinveld et al, 1993).

Fluorescence of LDL was determined at $360 \mathrm{~nm}$ excitation and $430 \mathrm{~nm}$ emission on a Shimadzu RF5000 spectrofluorophotometer. Susceptibility of LDL to in vitro oxidation was determined by monitoring formation of conjugated dienes at $234 \mathrm{~nm}$ on a PE-lambda 12 spectrophotometer (Perkin Elmer Ltd., Beaconsfield, United Kingdom) as described by Esterbauer et al (1989) and as modified by Kleinveld et al (1992). Lagtime, defined as the time interval between the intercept of the linear least-square slope of the absorbance curve with the initial absorbance axis, was taken as a measure of resistance to oxidation. LDL agarose electrophoresis was performed as described earlier (De Graaf et al, 1991), using Paragon lipo gels (Beckman, Fullerton, California).

\section{Data Analysis and Statistics}

The computer program ASTUTE (Microsoft Inc., Redmond, Washington) was used for the analysis. Data are presented as means \pm SD and were evaluated by using Student's $t$ test for paired and unpaired data. Linear regression analysis (and Pearson correlation test) were performed to examine the relationship between variables.

\section{References}

Attman PO, Samuelsson O, and Alaupovic P (1993). Lipoprotein metabolism and renal failure. Am J Kidney Dis 21:573592.

Bos JC, Grooteman MP, van Houte AJ, Schoorl M, van Limbeek J, and Nube MJ (1997). Low polymorphonuclear cell degranulation during citrate anticoagulation: A comparison between citrate and heparin dialysis. Nephrol Dial Transplant 12:1387-1393.

Cases A, Reverter JC, Escolar G, Sanz C, Lopez-Pedret J, Revert L, and Ordinas A (1993). Platelet activation on hemodialysis: Influence of dialysis membranes. Kidney Int Suppl 41:S217-S220.

Cominacini L, Pasini AF, Garbin U, Davoli A, Tosetti ML, Campagnola M, Rigoni A, Pastorino AM, Lo Cascio V, and Sawamura T (2000). Oxidized low density lipoprotein (oxLDL) binding to ox-LDL receptor-1 in endothelial cells induces the activation of NF-kappaB through an increased production of intracellular reactive oxygen species. J Biol Chem 275:12633-12638.

Cominacini L, Rigoni A, Pasini AF, Garbin U, Davoli A, Campagnola M, Pastorino AM, Lo Cascio V, and Sawamura $T$ (2001). The binding of oxidized low density lipoprotein (oxLDL) to oxLDL receptor-1 reduces the intracellular concentration of nitric oxide in endothelial cells through an increased production of superoxide. J Biol Chem 276: 13750-13755.

Conti M, Morand PC, Levillain P, and Lemonnier A (1991). Improved fluorometric determination of malonaldehyde. Clin Chem 37:1273-1275.

Davi G, Alessandrini P, Mezzetti A, Minotti G, Bucciarelli T, Costantini F, Cipollone F, Bon GB, Ciabattoni G, and Patrono C (1997). In vivo formation of 8-epi-prostaglandin F2 alpha in hypercholesterolemia. Arterioscler Thromb Vasc Biol 17: 3230-3235.

De Graaf J, Hak-Lemmers HL, Hectors MP, Demacker PN, Hendriks JC, and Stalenhoef AF (1991). Enhanced susceptibility to in vitro oxidation of the dense low-density lipoprotein subfraction in healthy subjects. Arterioscler Thromb 11:298306.

Demacker PN, Hessels M, Toenhake-Dijkstra H, and Baadenhuijsen $H$ (1997). Precipitation methods for high-density lipoprotein cholesterol measurement compared, and final evaluation under routine operating conditions of a method with a low sample-to-reagent ratio. Clin Chem 43:663-668.

Demacker PN, Sommeren-Zondag DF, Stalenhoef AF, Stuyt PM, and van't Laar A (1983). Ultracentrifugation in swingingbucket and fixed-angle rotors evaluated for isolation and determination of high-density lipoprotein subfractions HDL2 and HDL3. Clin Chem 29:656-663.

Demuth K, Myara I, Chappey B, Vedie B, Pech-Amsellem MA, Haberland ME, and Moatti N (1996). A cytotoxic electronegative LDL subfraction is present in human plasma. Arterioscler Thromb Vasc Biol 16:773-783.

Devaraj S and Jialal I (1997). Laboratory assessment of lipoprotein oxidation. In: Rifai N, Warnick GRA, and Dominiczak M, editors. Handbook of lipoprotein testing. Washington, DC: AACC Press, 357-373.

Ehara S, Ueda M, Naruko T, Haze K, Itoh A, Otsuka M, Komatsu R, Matsuo $\mathrm{T}$, Itabe $\mathrm{H}$, Takano $\mathrm{T}$, Tsukamoto $\mathrm{Y}$, Yoshiyama M, Takeuchi K, Yoshikawa J, and Becker AE (2001). Elevated levels of oxidized low density lipoprotein show a positive relationship with the severity of acute coronary syndromes. Circulation 103:1955-1960.

Esterbauer H, Striegl G, Puhl H, and Rotheneder M (1989). Continuous monitoring of in vitro oxidation of human low density lipoprotein. Free Radic Res Commun 6:67-75.

Foley RN and Parfrey PS (1998). Cardiovascular disease and mortality in ESRD. J Nephrol 11:239-245.

Foley RN, Parfrey PS, and Sarnak MJ (1998). Clinical epidemiology of cardiovascular disease in chronic renal disease. Am J Kidney Dis 32:S112-S119. 
Friedewald WT, Levy RI, and Fredrickson DS (1972). Estimation of the concentration of low-density lipoprotein cholesterol in plasma, without use of the preparative ultracentrifuge. Clin Chem 18:499-502.

Goldstein JL, Hobbs HH, and Brown MS (1995). Familial hypercholesterolemia. In: Scriver CR, Beaudet AL, Sly WS, and Valle D, editors. The metabolic basis of inherited disease. London: Macmillan magazines, 1981-2030.

Haberland ME, Fogelman AM, and Edwards PA (1982). Specificity of receptor-mediated recognition of malondialdehyde-modified low density lipoproteins. Proc Natl Acad Sci USA 79:1712-1716.

Handelman GJ, Walter MF, Adhikarla R, Gross J, Dallal GE, Levin NW, and Blumberg JB (2001). Elevated plasma F2isoprostanes in patients on long-term hemodialysis. Kidney Int 59:1960-1966.

Haraki T, Takegoshi T, Kitoh C, Kajinami K, Wakasugi T, Hirai J, Shimada T, Kawashiri M, Inazu A, Koizumi J, and Mabuchi H (2001). Hyperhomocysteinemia, diabetes mellitus, and carotid atherosclerosis independently increase atherosclerotic vascular disease outcome in Japanese patients with end-stage renal disease. Clin Nephrol 56:132-139.

Holvoet P, Donck J, Landeloos M, Brouwers E, Luijtens K, Arnout J, Lesaffre E, Vanrenterghem Y, and Collen D (1996). Correlation between oxidized low density lipoproteins and von Willebrand factor in chronic renal failure. Thromb Haemost 76:663-669.

Holvoet P, Mertens A, Verhamme P, Bogaerts K, Beyens G, Verhaeghe R, Collen D, Muls E, and Van de WF (2001). Circulating oxidized LDL is a useful marker for identifying patients with coronary artery disease. Arterioscler Thromb Vasc Biol 21:844-848.

Holvoet P, Perez G, Zhao Z, Brouwers E, Bernar H, and Collen D (1995). Malondialdehyde-modified low density lipoproteins in patients with atherosclerotic disease. J Clin Invest 95:2611-2619.

Holvoet P, Stassen JM, Van Cleemput J, Collen D, and Vanhaecke J (1998a). Oxidized low density lipoproteins in patients with transplant-associated coronary artery disease. Arterioscler Thromb Vasc Biol 18:100-107.

Holvoet P, Vanhaecke J, Janssens S, Van de Werf, and Collen D (1998b). Oxidized LDL and malondialdehydemodified LDL in patients with acute coronary syndromes and stable coronary artery disease. Circulation 98:1487-1494.

Hulthe J, Wikstrand J, Lidell A, Wendelhag I, Hansson GK, and Wiklund O (1998). Antibody titers against oxidized LDL are not elevated in patients with familial hypercholesterolemia. Arterioscler Thromb Vasc Biol 18:1203-1211.

Islam KN, O’Byrne D, Devaraj S, Palmer B, Grundy SM, and Jialal I (2000). Alpha-tocopherol supplementation decreases the oxidative susceptibility of LDL in renal failure patients on dialysis therapy. Atherosclerosis 150:217-224.

Itabe H, Yamamoto H, Imanaka T, Shimamura K, Uchiyama H, Kimura J, Sanaka T, Hata Y, and Takano T (1996). Sensitive detection of oxidatively modified low density lipoprotein using a monoclonal antibody. J Lipid Res 37:4553.

Jackson P, Loughrey CM, Lightbody JH, McNamee PT, and Young IS (1995). Effect of hemodialysis on total antioxidant capacity and serum antioxidants in patients with chronic renal failure. Clin Chem 41:1135-1138.
Kleinveld HA, Hak-Lemmers HL, Stalenhoef AF, and Demacker PN (1992). Improved measurement of low-density lipoprotein susceptibility to copper-induced oxidation: Application of a short procedure for isolating low-density lipoprotein. Clin Chem 38:2066-2072.

Kleinveld HA, Naber AHJ, Stalenhoef AFH, and Demacker PNM (1993). Oxidation resistance, oxidation rate, and extent of oxidation of human low-density lipoprotein depend on the ratio of oleic acid content to linoleic acid content: Studies in vitamin E deficient subjects. Free Radic Biol Med 15:273280.

Kotze MJ, Davis HJ, Bissbort S, Langenhoven E, Brusnicky J, and Oosthuizen CJ (1993). Intrafamilial variability in the clinical expression of familial hypercholesterolemia: Importance of risk factor determination for genetic counselling. Clin Genet 43:295-299.

Kume N, Murase T, Moriwaki H, Aoyama T, Sawamura T, Masaki T, and Kita T (1998). Inducible expression of lectinlike oxidized LDL receptor- 1 in vascular endothelial cells. Circ Res 83:322-327.

Lavrencic A, Kosmina B, Keber I, Videcnik V, and Keber D (1996). Carotid intima-media thickness in young patients with familial hypercholesterolaemia. Heart 76:321-325.

Li D and Mehta JL (2000a). Antisense to LOX-1 inhibits oxidized LDL-mediated upregulation of monocyte chemoattractant protein-1 and monocyte adhesion to human coronary artery endothelial cells. Circulation 101:2889-2895.

Li D and Mehta JL (2000b). Upregulation of endothelial receptor for oxidized LDL (LOX-1) by oxidized LDL and implications in apoptosis of human coronary artery endothelial cells: Evidence from use of antisense LOX-1 mRNA and chemical inhibitors. Arterioscler Thromb Vasc Biol 20:11161122.

Lindner A, Charra B, Sherrard DJ, and Scribner BH (1974). Accelerated atherosclerosis in prolonged maintenance hemodialysis. N Engl J Med 290:697-701.

Locatelli F, Del Vecchio L, and Manzoni C (1998). Morbidity and mortality on maintenance haemodialysis. Contrib Nephrol 124:166-189.

Loughrey CM, Young IS, Lightbody JH, McMaster D, McNamee PT, and Trimble ER (1994a). Oxidative stress in haemodialysis. QJM 87:679-683.

Loughrey CM, Young IS, McEneny J, McDowell IF, McMaster C, McNamee PT, and Trimble ER (1994b). Oxidation of low density lipoprotein in patients on regular haemodialysis. Atherosclerosis 110:185-193.

Lowry OH, Rosebrough NJ, Farr AL, and Randall RJ (1951). Protein measurement with the Folin phenol reagent. J Biol Chem 193:265-275.

Maggi E, Bellazzi R, Falaschi F, Frattoni A, Perani G, Finardi G, Gazo A, Nai M, Romanini D, and Bellomo G (1994a). Enhanced LDL oxidation in uremic patients: An additional mechanism for accelerated atherosclerosis? Kidney Int 45: 876-883.

Maggi E, Bellazzi R, Gazo A, Seccia M, and Bellomo G (1994b). Autoantibodies against oxidatively-modified LDL in uremic patients undergoing dialysis. Kidney Int 46:869-876.

Moriwaki H, Kume N, Sawamura T, Aoyama T, Hoshikawa H, Ochi H, Nishi E, Masaki T, and Kita T (1998). Ligand specificity of LOX-1, a novel endothelial receptor for oxidized low 
density lipoprotein. Arterioscler Thromb Vasc Biol 18:15411547.

Morrow JD (2000). The isoprostanes: Their quantification as an index of oxidant stress status in vivo. Drug Metab Rev 32:377-385.

Myant NB (1983). The metabolic basis of familial hypercholesterolemia. Klin Wochenschr 61:383-401.

Nourooz-Zadeh J, Smith CC, and Betteridge DJ (2001). Measures of oxidative stress in heterozygous familial hypercholesterolaemia. Atherosclerosis 156:435-441.

O’Byrne D, Devaraj S, Islam KN, Collazo R, McDonald L, Grundy S, and Jialal I (2001). Low-density lipoprotein (LDL)induced monocyte-endothelial cell adhesion, soluble cell adhesion molecules, and autoantibodies to oxidized-LDL in chronic renal failure patients on dialysis therapy. Metabolism 50:207-215.

Pannier B, Guerin AP, Marchais SJ, Metivier F, Safar ME, and London GM (2000). Postischemic vasodilation, endothelial activation, and cardiovascular remodeling in end-stage renal disease. Kidney Int 57:1091-1099.

Panzetta O, Cominacini L, Garbin U, Fratta PA, Gammaro L, Bianco F, Davoli A, Campagnola M, De Santis A, Pastorino AM, et al (1995). Increased susceptibility of LDL to in vitro oxidation in patients on maintenance hemodialysis: Effects of fish oil and vitamin E administration. Clin Nephrol 44:303309.

Ross R (1986). The pathogenesis of atherosclerosis: An update. N Engl J Med 314:488-500.

Ross R (1993). The pathogenesis of atherosclerosis: A perspective for the 1990s. Nature 362:801-809.

Sanchez-Quesada JL, Otal-Entraigas C, Franco M, Jorba O, Gonzalez-Sastre F, Blanco-Vaca F, and Ordonez-Llanos J (1999). Effect of simvastatin treatment on the electronegative low-density lipoprotein present in patients with heterozygous familial hypercholesterolemia. Am J Cardiol 84:655-659.

Savage T, Clarke AL, Giles M, Tomson CR, and Raine AE (1998). Calcified plaque is common in the carotid and femoral arteries of dialysis patients without clinical vascular disease. Nephrol Dial Transplant 13:2004-2012.

Sawamura T and Inoue K (2001). Accelerated atherogenesis in mice overexpressing LOX-1. Circulation 104(Suppl II):272.

Sawamura T, Kume N, Aoyama T, Moriwaki H, Hoshikawa H, Aiba Y, Tanaka T, Miwa S, Katsura Y, Kita T, and Masaki T (1997). An endothelial receptor for oxidized low-density lipoprotein. Nature 386:73-77.
Sevanian A, Hwang J, Hodis H, Cazzolato G, Avogaro P, and Bittolo-Bon G (1996). Contribution of an in vivo oxidized LDL to LDL oxidation and its association with dense LDL subpopulations. Arterioscler Thromb Vasc Biol 16:784-793.

Simon Broome Register Group (1991). Risk of fatal coronary heart disease in familial hypercholesterolaemia. Scientific Steering Committee on behalf of the Simon Broome Register Group. BMJ 303:893-896.

Slack J (1969). Risks of ischaemic heart-disease in familial hyperlipoproteinaemic states. Lancet 2:1380-1382.

Smilde TJ, van den Berkmortel FW, Boers GH, Wollersheim $H$, de Boo $T$, van Langen $H$, and Stalenhoef AF (1998). Carotid and femoral artery wall thickness and stiffness in patients at risk for cardiovascular disease, with special emphasis on hyperhomocysteinemia. Arterioscler Thromb Vasc Biol 18:1958-1963.

Steinberg D and Lewis A (1997). Conner Memorial Lecture. Oxidative modification of $\mathrm{LDL}$ and atherogenesis. Circulation 95:1062-1071.

Thompson GR, Seed M, Niththyananthan S, McCarthy S, and Thorogood M (1989). Genotypic and phenotypic variation in familial hypercholesterolemia. Arteriosclerosis 9:175-180.

Tonstad S, Joakimsen O, Stensland-Bugge E, Ose L, Bonaa $\mathrm{KH}$, and Leren TP (1998). Carotid intima-media thickness and plaque in patients with familial hypercholesterolaemia mutations and control subjects. Eur J Clin Invest 28:971-979.

Toshima S, Hasegawa A, Kurabayashi M, Itabe H, Takano T, Sugano J, Shimamura K, Kimura J, Michishita I, Suzuki T, and Nagai R (2000). Circulating oxidized low density lipoprotein levels: A biochemical risk marker for coronary heart disease. Arterioscler Thromb Vasc Biol 20:2243-2247.

Van den Akker JM, Bredie SJH, Diepenveen SHA, Van Tits LJH, Stalenhoef AFH, and Van Leusen R (In press, 2003). Atorvastatin and simvastatin in patients on hemodialysis: Effects on lipoproteins, c-reactive protein and in vivo oxidized LDL. J Nephrol.

van Tits LJ, de Waart F, Hak-Lemmers HL, van Heijst $P$, de Graaf J, Demacker PN, and Stalenhoef AF (2001). Effects of alpha-tocopherol on superoxide production and plasma intercellular adhesion molecule- 1 and antibodies to oxidized LDL in chronic smokers. Free Radic Biol Med 30:1122-1129.

Witztum JL and Steinberg D (1991). Role of oxidized low density lipoprotein in atherogenesis. J Clin Invest 88:17851792. 